\section{O SUJEITO DAS NEUROCIÊNCIAS}

THE SUBJECT OF THE NEUROSCIENCES

\author{
Monah Winograd ${ }^{1}$
}

Resumo Este ensaio trata da noção de subjetividade com a qual as neurociências operam, mas também aponta para o que tem sido o assunto principal e a pretensão desta disciplina no século XXI: a ideia de que o pensamento em sentido lato e a experiência subjetiva podem ser entendidos e explicados pela atividade de nossos neurônios. A versão mainstream dos estudos sobre o cérebro parte da premissa - que eles não discutem - de que o pensamento deriva do funcionamento cerebral e é basicamente determinado por ele. Se penso como penso, se sinto o que sinto, se faço o que faço, enfim, se sou como sou, é porque meu cérebro é como é. Encontro-me, assim, condensado e aprisionado neste órgão transformado em piloto de mim mesmo. Investigamos esta problemática, destacando as estatísticas sobre o consumo de psicofármacos, a história da vinculação entre cérebro e pensamento e, por fim, os programas de pesquisa em neurociências.

Palavras-chave neurociências; sujeito; cérebro; pensamento.
Abstract This essay discusses the notion of subjectivity under which the neurosciences operate, but also points to what has been the main topic and goal of this subject in the 21t century: the idea that thinking broadly and subjective experiences can be understood and explained by the activity of our neurons. The mainstream version of the studies on the brain part from the premise - which they do not argue - that thought derives from the cerebral functions and is basically determined by it. If I think as I do, if I feel what I feel, if I do what I do, in sum, if I am as I am, it is because my brain is how it is. Thus, I find myself condensed and trapped in this organ, turned into a pilot of myself. We investigate this issue, highlighting the statistics on psychotropic drug use, the history of the connection between the brain and thought and, finally, the research programs in neuroscience.

Keywords neurosciences; subject; brain; thought. 


\section{Introdução}

Nos últimos trinta anos, assistimos à consolidação explícita deste projeto de naturalização do pensamento e de condensação do sujeito no cérebro. Como consequência, testemunhamos uma mudança fundamental no modo como compreendemos a nós mesmos e nosso sofrimento psíquico. Às descrições psicológicas e culturalistas em geral seguiram-se as descrições fisicalistas, cerebrais e genéticas apoiadas na grande quantidade de informações novas, produzidas pelas neurociências (NC), sobre as bases biológicas da experiência subjetiva. Particularmente os saberes 'psi' se viram cada vez mais próximos de sua consolidação como ciências positivas e fisicalistas, capazes de explicar neuroquimicamente a complexidade da vida subjetiva. O projeto geral é encontrar, para os fenômenos psíquicos individuais, descrições universais referidas à neurobiologia da espécie humana e, portanto, imunes a quaisquer contaminações ideológicas, humanistas ou subjetivistas (Winograd, 2009).

Este modo de pensar trouxe inúmeras consequências teóricas, clínicas e éticas. No campo das terapêuticas psicológicas, por exemplo, tem havido uma substituição progressiva das técnicas psicodinâmicas pelas técnicas cognitivocomportamentais, supostamente mais rápidas e precisas porque são consideradas objetivas. A clínica psiquiátrica, por sua vez, assumiu como função principal operar no registro físico - supostamente a causa primeira dos mal-estares psíquicos - por meio de intervenções medicamentosas (Winograd, 2009).

Em 1998, a Organização Mundial de Saúde (OMS) estimou que 24\% dos pacientes que procuravam médicos de cuidados primários sofriam de um transtorno mental definido pela Classificação Estatística Internacional de Doenças e Problemas Relacionados com a Saúde. Dentre estes pacientes, $69 \%$ também apresentavam sintomas físicos (WHO, 1998). Em 2008, verificou-se que $14 \%$ da carga de impacto global de doenças - calculada a partir de índices de mortalidade, de morbidade e de inaptidão - podiam ser atribuídos às doenças mentais, neurológicas e relacionadas ao uso e abuso de substâncias (WHO, 2008). Kessler e colaboradores (2007) estimaram que aproximadamente metade da população norte-americana, alguma vez na vida, responderá aos critérios para algum transtorno classificado pelo DSM IV (Diagnostic and Statistical Manual of Mental Disorders).

Esses dados epidemiológicos merecem discussão. Conforme observam Ehrenberg e Lovell (2001), o domínio de ação da medicina e da clínica das doenças mentais abrange hoje desde as esquizofrenias até as performances individuais cotidianas, expressando, na verdade, uma ampliação do espectro da psicopatologia com a inclusão do mal-estar psíquico rotineiro no seu campo de atenção e de intervenção. Isto se deve ao fato de que, como sublinham Ehrenberg e Lovell (2001), na virada do século XX para o XXI, a 
psiquiatria tornou-se responsável não somente por tratar das doenças mentais, mas também por promover a saúde mental em geral.

Com efeito, o projeto de promoção da higiene mental data dos séculos XVIII e XIX, quando a mesma foi imposta por higienistas e pedagogos como norma social. Tratava-se de educar psicologicamente a população a fim de universalizar alguns traços subjetivos e emocionais definidos então como saudáveis, ou seja, estabelecer modelos dominantes com base em normas psicológicas que fixassem certos registros de percepção e de interpretação dos fenômenos psíquicos (Costa, 1984).

Disto resultou, de um lado, o aumento da capacidade de tradução das sensações psíquicas em sintomas psicopatológicos (Costa, 1984) e, de outro lado, o crescimento do consumo da saúde mental (e não da taxa de sanidade mental). Por exemplo, Lane (2007) denunciou a transformação da vergonha em transtorno psiquiátrico através da inclusão da fobia social no quadro dos transtornos de ansiedade em 1980. Por sua vez, Horwitz e Wakefield (2007), impressionados com a medicalização crescente das misérias psíquicas banais, entenderam que a psiquiatria atual confunde tristeza normal com transtorno depressivo, devido à pouca importância conferida à relação existente entre o sintoma e o contexto no qual ele emerge. Já Kessler e colaboradores (2007), após compararem a prevalência de ataques isolados de pânico com a de transtorno do pânico com ou sem agorafobia, perceberam serem os ataques isolados de pânico bastante comuns e, por isso, sugeriram a reavaliação do critério diagnóstico e dos limiares sintomáticos para a definição da ocorrência de um transtorno. Pretendiam, com isso, forçar o estabelecimento de uma diferenciação rigorosa entre as experiências normais de angústia e as experiências patológicas do pânico.

Esta ampliação da definição dos quadros de patologia mental trouxe como consequência um aumento considerável na produção e no consumo de medicamentos psicotrópicos (Ehrenberg e Lovell, 2001). Instaurou-se um mercado do equilíbrio subjetivo envolvendo e movimentando interesses que estão muito além da preocupação com a saúde mental dos indivíduos. Os medicamentos destinados ao tratamento das doenças mentais ocupavam, há mais ou menos vinte anos atrás, o nono lugar entre os mais vendidos mundialmente. Nessa mesma época, nos Estados Unidos, aproximadamente dois milhões de pessoas faziam uso de farmacoterapia, e o diazepam era o mais prescrito (APA, 1990).

De lá para cá, os números só aumentaram, tendo sido verificada uma mudança no padrão de prescrição de psicofármacos, com maior utilização de antidepressivos (APA, 1990). No Brasil, estudos realizados no final dos anos 1980, mostraram que foram consumidos quinhentos milhões de doses diárias de tranquilizantes (Carlini, 1995), o que, segundo a OMS (1990), representava uma quantidade três vezes superior às necessidades reais. 
Outro estudo realizado pelo Centro Brasileiro de Informações sobre Drogas Psicotrópicas (Cebrid) verificou que, em 2003, foram produzidas 33 bilhões de doses de benzodiazepínicos. Vale lembrar que o Brasil tem 37 benzodiazepínicos no comércio, que são vendidos por diferentes laboratórios farmacêuticos sob quase oitenta nomes e marcas diferentes (Cebrid, 2003). No caso das crianças, a situação não é diferente. Nos EUA, por exemplo, entre $2001 \mathrm{e}$ 2005, a prescrição de psicofármacos aumentou em torno de 75\%. No Brasil, estima-se que cerca de 2,5 milhões de crianças estejam tomando antidepressivos; entre 2002 e 2006, a produção brasileira de ritalina - droga prescrita para o Transtorno do Déficit de Atenção com Hiperatividade (TDAH) - cresceu 465\% (Itaborahy, 2009). Quanto aos antidepressivos, um estudo realizado pelo Centro de Pesquisa de Pediatria Farmacêutica da Universidade de Londres sugeriu um aumento de seu uso por crianças em nove países pesquisados, inclusive o Brasil, entre 2000 e 2002 (Wong et al., 2004).

Ora, não há dúvidas de que os psicofármacos contribuíram muito para minimizar algumas formas de sofrimento decorrentes de transtornos mentais como a psicose, por exemplo, já que ajudaram a diminuir significativamente o número de internações psiquiátricas e o tempo de permanência desses pacientes nos hospitais. A questão não é tanto esta, mas sim o fato de que testemunhamos, ao longo da segunda metade do século XX e do início do século XXI, uma tendência crescente de medicalização do mal-estar psíquico em suas mais variadas formas. Uma leitura possível para tais dados é o entendimento de que tais afecções expressam, mais profundamente, um processo de produção subjetiva apoiado na ideia de funcionalidade, de competência, de performance, de responsabilidade individual pelo próprio bemestar e pela própria felicidade. Qualquer desvio, variação ou dificuldade vira anormalidade. E cada estado de espírito visto como anormal tem ou terá em breve uma explicação neurocientífica para justificar a solução ao alcance das mãos: a tristeza combate-se com antidepressivos; a ansiedade, com tranquilizantes; a desatenção e a dispersão, com ritalina, e vai por aí. Ou seja, o que sentimos e pensamos deriva, em última instância, da dança intracerebral dos nossos neurônios e das substâncias que ali passeiam (Rosa e Winograd).

Somente os ingênuos discordariam de que o estado atual é, com efeito, o resultado de uma longa história das ideias e das práticas. Quais foram, então, os caminhos pelos quais chegamos a formular a ideia de que nosso pensamento poderia ser reduzido a estados e estruturas cerebrais? Qual a história desta ligação íntima que construímos entre o cérebro e o pensamento? Já nos anos 1980, o mestre dos mestres, Georges Canguilhem, denunciou esse projeto de naturalização do pensamento. Naquela ocasião, Canguilhem (1980) atacou ferozmente a pretensão de se criar uma ciência da mente baseada unicamente na correlação entre os estados e as funções psíquicas e os estados e as estruturas cerebrais. Ciência da mente para a qual o pensamento se 
tornaria um lugar vazio por ser compreendido somente como um produto, uma secreção do cérebro.

O mestre francês começou ressaltando o fato de que a questão de saber como pensamos e sentimos já deixou de ser puramente teórica, pois um número cada vez maior de poderes estão interessados em nossa faculdade de pensar. De modo que qualquer investigação crítica e rigorosa sobre o pensamento deveria, antes de tudo, ter como objetivo a defesa contra a incitação invasiva, dissimulada ou manifesta, a pensar como querem que pensemos. Noutras palavras, para o historiador das ideias, trata-se de chamar a atenção para uma extensão programada de técnicas que visam, em última análise, à naturalização do pensamento ou, em outros termos, à sua normatização. Daí ser necessário situar historicamente esta configuração de forças que Canguilhem entreviu. Assim como os biólogos entendem só ser possível falar do cérebro humano situando esse órgão no extremo de uma história dos seres vivos, também devemos relacionar essa questão do cérebro e do pensamento, antes de tudo, à história da cultura. Como, ao longo da história ocidental das ideias, cérebro e pensamento foram sendo estreitamente vinculados até resultar no quadro descrito acima?

Com efeito, este empreendimento não é novo. Um dos maiores filósofos da Antiguidade, Aristóteles, ensinava que a função do cérebro, antagonista à do coração, é esfriar o corpo do animal. Foi Hipócrates quem ensinou ser o cérebro a sede das sensações, o órgão dos movimentos e do juízo. Embora Platão retome em parte a doutrina hipocrática, devemos a Galeno sua imposição na cultura ocidental através da busca de sua confirmação por meio de experiências muito engenhosas no sistema nervoso e no cérebro (Canguilhem, 1980). Por sua vez, o século XIX conheceu a consolidação destas ideias nos trabalhos de Franz Joseph Gall, com quem começou efetivamente a ciência do cérebro sob a forma da frenologia e da cranioscopia. O ponto forte da doutrina de Gall era a exclusividade que ele atribuía ao encéfalo e, mais especialmente, aos hemisférios cerebrais como sede de todas as faculdades intelectuais, morais e afetivas. O cérebro, entendido como um sistema de sistemas, era apresentado como o único suporte físico do quadro das faculdades - todo o resto do corpo era detalhe. Contra a ideia da aquisição da experiência sob a pressão do ambiente, Gall defendia o inatismo das qualidades morais, dos poderes intelectuais e das tendências afetivas; inatismo fundado sobre o substrato anatômico de um único órgão, o cérebro - questão que está longe de ser puramente teórica, como a história demonstrou nos anos que se seguiram e ainda hoje.

Embora se tenha ridicularizado bastante a corcova dos matemáticos (situada por um neurofisiologista alemão cognominado 'Gall redivivus' acima da órbita esquerda, no lado externo), ninguém ousa rir dos cromossomos dos superdotados, da hereditariedade genética do cociente intelectual ou da 
disfunção neuroquímica das crianças endiabradas. E mesmo que nosso cociente intelectual seja médio, conseguimos perfeitamente entrever as consequências possíveis deste enfoque no campo das condições sociais e das práticas pedagógicas, por exemplo. O próprio Gall já falava do alcance prático de suas teorias na área da pedagogia, da identificação das aptidões (o que hoje chamamos de orientação vocacional ou psicológica), na área da medicina e na esfera da segurança (através da prevenção da delinquência) (Canguilhem, 1980).

Igualmente na psicopatologia, a influência da frenologia não pode ser subestimada porque seria impossível entender como as primeiras localizações cerebrais das funções intelectuais ligadas aos problemas da fala e da memória das palavras tornaram-se verdadeiros dogmas científicos. Nomes célebres como Broca, Wernicke e Charcot foram alguns que confirmaram a localização da função da linguagem nos lóbulos anteriores do cérebro em meados do século XIX, sob o olhar reprovador de alguns jovens neurologistas como Sigmund Freud, para quem a linguagem deveria ser entendida como função do sistema como um todo, resultando da associação entre suas partes. No caso de lesão em alguma parte do sistema, seria o todo que funcionaria diferentemente.

Este pequeno retrospecto demonstra uma preocupação da atualidade, pois a explicação das funções cognitivas e afetivas pelo cérebro traz uma ambiguidade fundamental que as NC não conseguem resolver: quem ou o que é o sujeito? Quem ou o que diz eu? Estamos aqui no âmago da ambiguidade. A fórmula freudiana (Freud, 1933) - Wo Es war soll Ich werden ('onde isso está, o eu deve advir', tradução nossa do alemão) -, cuja interpretação divide as escolas de psicanálise, pode ser aproveitada para nosso uso. E a última frase do histórico que faz Canguilhem e é uma pergunta que as NC não respondem (embora pretendam fazê-lo assim que possível): como é que um sujeito, um 'eu penso', advém nisso que o neurofisiologista de hoje, depois do frenologista, indica e descreve? Nisso, um cérebro?

Quase 25 anos depois de Canguilhem, o sociólogo Alain Ehrenberg (2004) identificou os efeitos deste projeto de naturalização do pensamento através da circunscrição de uma figura antropológica que ele chamou de sujeito cerebral. Segundo o sociólogo, neste início do século, as NC têm se apresentado como a chave para o entendimento dos processos de aprendizagem, dos comportamentos sociais e das disfunções mentais. Ou seja, o projeto é fundir o social, o cerebral e o mental em uma nova ciência rainha.

Com efeito, nos anos 1980, as NC permitiram a produção de duas mudanças, como demonstram os dados estatísticos apresentados anteriormente: as doenças neurológicas e as doenças mentais se tornaram suscetíveis de serem abordadas como uma única espécie de doença; e o perímetro de ação da neurologia e da psiquiatria se estendeu às emoções, aos comportamentos sociais e aos sentimentos morais (Ehrenberg, 2004). Graças à 'imagearia' 
cerebral e às novas técnicas de biologia molecular que permitem ver o cérebro em atividade, anunciou-se o surgimento de uma biologia da consciência, do espírito, enfim, uma biologia da mente.

Exemplos não faltam. Nas revistas científicas de prestígio e na mídia em geral, temos visto o anúncio da identificação dos circuitos neurais de processos psíquicos os mais variados, desde a simpatia e o luto, passando pela decisão de compra e pela crença em Deus, até a violência e o amor. Ou seja, temos sido levados a crer que apreender o cérebro e seu funcionamento é indispensável para compreendermos a nós mesmos - ideia corrente entre os psicólogos cognitivistas que entendem ser o cérebro objeto da psicologia.

Contudo, Ehrenberg (2004) propõe sabiamente um deslocamento dos termos da discussão. Em vez de tomar partido na oposição entre o homem como ser corporal e cerebral versus o homem como ser social e falante (oposição tradicional em psiquiatria), deve-se perceber a instalação de um novo contexto no qual o sofrimento psíquico e a saúde mental tornaram-se os principais pontos de referência da individualização da condição humana em uma sociedade da autonomia generalizada. Nesta circunstância, as NC se oferecem como o aporte científico, tecnológico e médico para responder à demanda de saúde mental que se difundiu há vinte anos nas nossas sociedades. Para melhor entender o debate, o sociólogo propõe que se distinga nas NC um programa fraco e um programa forte. E, neste último, três perspectivas: uma teórica, uma prática e uma social.

O programa fraco em NC tem como objetivo o progresso no tratamento das doenças neurológicas através da descoberta dos aspectos neuropatológicos das doenças mentais. Trata-se, portanto, de uma abordagem que se pretende complementar à da psicologia, por exemplo. Ao lado de uma investigação sobre os aspectos subjetivos e psicológicos das psicopatologias ou das doenças neurológicas, pretende-se avançar no conhecimento dos aspectos neurobiológicos envolvidos (Ehrenberg, 2004).

Por sua vez, o programa forte associa, no plano filosófico, o conhecimento do cérebro ao conhecimento de si mesmo e, no plano clínico, fundir a neurologia e a psiquiatria em dois níveis. Em um deles, quer-se tratar as psicopatologias neurologicamente e, no outro nível, espera-se poder agir sobre o cérebro para aumentar nossas capacidades de decisão e de ação. Em sua versão maximalista, portanto, o programa forte tem o objetivo de produzir uma biologia do espírito ou uma neurobiologia da personalidade que seja uma biologia do indivíduo total. Noutras palavras, em sua perspectiva teórica, o programa forte visa a produzir uma explicação do espírito sobre uma base exclusivamente materialista através do postulado mais ou menos implícito de que o cérebro é o fundamento do espírito.

Esta perspectiva não é nova, mas o contexto atual de progresso científico e preocupação com o sofrimento psíquico e com a saúde mental faz dela uma 
perspectiva prática (profissional e terapêutica). Trata-se de, no campo da terapêutica, promover a fusão entre neurologia e psiquiatria, tratando as psicopatologias como problemas neurológicos. No campo profissional, por sua vez, a fusão entre o neurológico e o psicológico pretende fazer de todos os 'psis', 'neuros'. Já a perspectiva social pode ser verificada nas questões terapêuticas e além delas: o cérebro tem se tornado ator social e participado do modo como nos relacionamos conosco e com os outros.

Ehrenberg (2004) defende dois argumentos importantes. O primeiro deles expressa a ideia de que a redefinição em curso das fronteiras entre neurologia e psiquiatria não porá fim à tensão entre sujeito cerebral e sujeito falante, pois essa tensão é tão interna ao mundo da psiquiatria quanto à nossa forma de ver e de pensar a nós mesmos. O segundo argumento se refere à noção de que o programa forte seria um subproduto típico de nossa principal crença individualista, a saber, a de que o homem está primeiramente fechado na interioridade de seu corpo, lugar de sua verdade e que, em seguida, graças ao seu espírito, ele entra em relação com outrem para formar uma sociedade.

Para desenvolver seus argumentos, o autor realiza um percurso de análise em três movimentos. Inicialmente, resume os elementos da grande divisão que separou doenças da lesão e doenças da função, no final do século XIX - divisão que o programa forte pretende superar. A seguir, discute dois argumentos recorrentes na literatura científica: a existência de uma ponte entre o cérebro e o espírito, e a relação entre a especificidade biológica de um indivíduo e a especificidade do mesmo indivíduo como ser social. Finalmente, interroga o contexto social que leva a considerar o cérebro como um indivíduo e a se pensar a si próprio como um cérebro são ou enfermo - contexto social do surgimento da figura antropológica do sujeito cerebral.

Hoje, testemunhamos um processo de banalização da ideia de neurobiologia do sujeito humano, ou seja, de um cérebro assimilado a este sujeito. Vimos que os objetivos do programa forte em NC são basicamente compreender os mecanismos celulares e moleculares na esperança de que se possa agir sobre o cérebro para modificar os estados mentais e criar uma penicilina da doença mental. Ora, as implicações disto são evidentes: acaba-se com a grande divisão estabelecida entre 1880 e o começo do século XX entre doenças da lesão e doenças da função, divisão que permitiu estabelecer sobre uma base clínica as fronteiras entre neurologia e psiquiatria (Ehrenberg, 2004).

O paradigma da divisão entre neurologia e psiquiatria foi a histeria. Através dela, foi possível construir a ideia de psiquismo e lhe dar um conteúdo diferente de uma lesão cerebral. Vejamos como. No final do século XIX, para falar de doença era preciso haver uma lesão explicando o mal. Mas, no caso da histeria, não era possível identificar nenhuma lesão anatômica na necropsia do cérebro dos pacientes. Por isso, sem renunciar à suposição de 
que haveria uma lesão na origem do quadro, Charcot propôs o termo lesão funcional ou lesão dinâmica. Mas tal proposição trouxe uma consequência importante: a revisão da consideração, corrente até então, da histeria como simulação ou, quando muito, doença imaginária. Ou seja, a partir de Charcot, a histeria passou a ser considerada como patologia neurológica autêntica cujo entendimento exclui qualquer psicologia (não se trata de fingimento nem de imaginação) e qualquer referência a algum psiquismo. É que, para Charcot, o signo discriminante da histérica é sua capacidade de ser sugestionada pela hipnose, a qual produz uma reação fisiológica (e não psicológica). Com isso, ele salvou o estatuto da doença histérica, abrigando-a solidamente no rincão da neurologia.

Contudo, a desqualificação posterior da concepção charcotiana provocou duas consequências interessantes: deu origem a uma psicopatologia, pois, às doenças imaginárias sucederam as doenças da imaginação e reduziu o perímetro de ação da neurologia com o surgimento de inúmeras psicoterapias, dentre elas a psicanálise (Castel, 1998). Bernheim, o grande adversário de Charcot, contestava a ideia de que todas as pessoas podem ser hipnotizáveis e não só as histéricas. Para ele, Charcot acertou ao perceber que as histéricas não enganam o médico, pois estão verdadeiramente doentes. Mas, se enganou ao considerar a histeria como uma questão neurológica e fisiológica, pois a histeria evidenciava uma outra objetividade, diferente daquela dos médicos e fisiologistas. Com isso, consolidava-se a autonomização da função relativamente à lesão, e os problemas funcionais passavam a ser entendidos de modo próximo ao sentido atual da expressão e sem o recurso de uma base orgânica para explicar o mal. Mas Bernheim acrescentou algo mais: se nem todos podem ser hipnotizáveis é porque há algo, no sujeito, que aceita ou recusa algo de puramente pessoal. Eis a outra objetividade: afirmava-se a existência do subjetivo (Ehrenberg, 2004).

Contudo, o chefe de clínica de Charcot, Babinski, ao contrário de Bernheim, afirmava ser impossível saber se a histérica fantasia ou não, levando à eliminação da subjetividade, pois ela nada teria a ver com neurologia e com as doenças mentais que pertencem à psiquiatria. Desse modo, Babinski, contribuiu para o estabelecimento da fronteira entre o neurológico e o psicológico ao questionar a possibilidade de compreender os estados mentais a partir dos cerebrais (Ehrenberg, 2004).

Mas é exatamente isto o que pretende o programa forte contemporâneo: compreender a mente por meio do cérebro. De modo que este programa em NC está, a um só tempo, em oposição a Freud e à psicanálise, que apresentam os problemas em termos de relações fantasmáticas, mas também a Babinski, que eliminava uma subjetividade hoje reintroduzida.

Em resumo, o período que vai do fim do século XIX ao início do XX vê estabelecer-se uma separação, fundada sobre a clínica: de um lado, o sujeito 
cerebral da neurologia e, de outro, o sujeito falante da psicopatologia. No primeiro, o sintoma transcende o paciente que tem uma doença do sistema nervoso (é seu cérebro o ponto de imputação da terapêutica). No segundo, o sintoma é inteiramente singular ao paciente que está doente de si mesmo e de seu desejo (Ehrenberg, 2004).

Devemos, então, perguntar: seriam as NC a denominação de uma nova neurologia com um programa infinitamente mais ambicioso do que o de Babinski, pois cruzaria a fronteira entre estar doente do cérebro e estar psicologicamente doente? Seria esta ambição favorecida por um contexto que coloca a subjetividade e o sofrimento psíquico no centro da vida social? Em que medida progressos científicos e sentidos dados à vida social se misturam - ou seja, em que medida conceitos e contextos se misturam?

Antes, porém, de deter-se nestas questões, o autor investiga alguns argumentos recorrentes na literatura científica do começo deste século. $\mathrm{O}$ mais importante refere-se à suposição de que há uma ponte entre o cérebro e o espírito, a qual será possível atravessar um dia. Ora, para a biologia de modo geral, o ser é segundo o seu corpo, ou seja, deve-se metodologicamente reduzi-lo ao corpo para que o trabalho do biólogo possa ser feito.

Dito de outro modo, por rigor metodológico, os biólogos devem neutralizar o social, pois, sem tal procedimento, não se poderiam experimentar as hipóteses e nem estabelecer correlações estatísticas válidas. Daí a surpresa assustadora diante da verificação de que numerosas especulações biológicas sobre o espírito dão um passo a mais, que é, com efeito, um passo demais (Ehrenberg, 2004. Em vez da necessária neutralização metodológica do social revelam, em verdade, sua cegueira conceitual: a abordagem do ser segundo o corpo sendo assimilada, implícita ou explicitamente, ao ser considerado em sua totalidade.

Eis um erro metodológico e antropológico relativo à questão das relações entre o sujeito humano e seu corpo, entre o todo e a parte. À pergunta sobre como o cérebro produz os estados mentais, a literatura científica responde com a hipótese de uma ponte entre o cérebro e a mente (ou entre os mecanismos moleculares e os estados mentais). Eis um problema conceitual enorme e revelador: a biologia faz dos mecanismos cerebrais o sujeito, o ator das operações mentais, revelando uma confusão entre dois tipos de fenômenos. Ehrenberg (2004) lembra que François Jacob (1997) - que é biólogo, mas não neurobiólogo - afirmou sermos uma mistura perigosa de ácidos nucleicos e de lembranças, de desejos e de proteínas. Mas seremos compostos, no mesmo sentido, de proteínas e de desejos? É preciso diferenciar as duas espécies de fenômenos.

O sociólogo recorre a Wittgenstein (1982) e à sua diferenciação entre causas e razões. As causas são a expressão de uma regularidade natural, constatável empiricamente e previsível. Caracterizam-se pela exterioridade 
da causa e do efeito considerados como dois acontecimentos independentes. Além disso, as causas não têm autor. Por exemplo, a formação de uma proteína é o objeto de uma hipótese verificável: ao se descobrir a causa para a proteína ' $x$ ', tal causa, nas mesmas condições, agirá necessariamente para formar sempre a mencionada proteína.

Já as razões (ou motivos) têm autor. A razão é o que dá inteligibilidade e sentido a uma ação. Noutros termos, uma razão é uma interpretação de nossas ações, não é imposta pelos fatos e é regulada pela linguagem: uma razão justifica uma ação em função da relação entre o autor da ação e o outro, em função do contexto e da vida social. Por exemplo, a afirmação de que "eu não me lembro mais porque bati em João" refere-se não a uma causa, mas a uma razão, uma justificativa. E a culpa que sinto por ter batido no João, embora apresente uma mediação no nível molecular e químico, só é deflagrada cerebralmente se eu tiver razões (imaginárias ou reais) para me sentir culpado com relação a outro sujeito, dentro de um contexto.

Ou seja, pretender resolver o problema psicofísico substituindo a alma etérea dos filósofos pela alma material e tangível das NC é confundir causas e razões. Por isso, a distinção entre causas e razões dever ser considerada hierárquica. A mecânica causal do cérebro é englobada no universo das significações do qual ela deriva, pois as significações implicam a proeminência dos valores e regras sobre o corpo ou o cérebro (Ehrenberg, 2004).

Esta distinção entre causas e razões pode ser decalcada sobre uma outra distinção entre individuação e individualização. A individuação se refere à diferença entre os indivíduos no nível da identidade biológica, do que faz cada cérebro ser tão singular quanto as impressões digitais. Já a individualização diz respeito à diferença entre os indivíduos no nível da identidade da pessoa considerada em sua totalidade, ou melhor, em termos de suas relações significantes. Assim, se o nível das causas articula-se ao nível da individuação, o nível das razões é o mesmo nível da individualização.

Ora, a perspectiva naturalista do programa forte alinha a consideração do ser a partir do corpo (neste caso, do cérebro) e a consideração do ser como um ser pensante e atuante. E mais: ela faz do segundo a consequência do primeiro, estabelecendo uma confusão entre individuação (causas) e individualização (razões), levando a pensar que o cérebro é, ao mesmo tempo, o sujeito que dirige a pessoa e a pessoa inteira. É preciso, portanto, manter a distinção entre a identidade no seio da espécie (individuação) e o sentido que atribuímos a esta identidade e que não reside no cérebro, mas na vida social (na individualização). Eis porque, apesar das suas ambições, o programa forte em NC só pode produzir uma biologia da individuação, jamais da individualização.

Mas o programa forte apresenta perspectivas práticas que podem ser resumidas na sua intenção de integrar psiquiatria e neurologia, através da 
identificação entre sujeito como um todo e sujeito cerebral. Contra estes objetivos, Ehrenberg (2004) arrola os seguintes argumentos: o primeiro referese ao plano do diagnóstico: o acento posto sobre as causas biológicas impede que um diagnóstico diferencial conduza a cuidados terapêuticos diversificados e personalizados, segundo a sintomatologia específica de cada caso. O autismo é um bom exemplo, pois a clínica revela que relações patogênicas durante os primeiros anos podem produzir o mesmo tipo de sintoma que um problema no neurodesenvolvimento, de natureza genética e constitucional; o segundo argumento diz respeito ao plano clínico: não é difícil perceber que uma causa biológica ou a própria doença suscitam problemas psicopatológicos ou distúrbios funcionais, acentuando dificuldades gerais (relacionais e sociais) de pacientes neurológicos, por exemplo. Não por acaso, o neurologista Oliver Sacks (1985), entre outros, tem se dedicado ao relato psicológico aprofundado desses pacientes.

Ou seja, mesmo quando os pacientes psicóticos se tornarem pacientes neurológicos, a psicopatologia não desaparecerá. Para Ehrenberg (2004) a divisão entre neurologia e psiquiatria não poderá ser suprimida, assim como não se poderá eliminar a distinção entre doenças da função e doenças da lesão. Trocando em miúdos, para o autor, apesar das pretensões do programa forte, não será possível descartar o adjetivo 'mental', muito embora estejam tentando nos levar a crer que nos livramos de uma subjetividade que passa pela linguagem em proveito de uma subjetividade cerebral, que é, em verdade, uma subjetividade do autômato, mínima, asseguradora, difundida e legitimada na socialização do cérebro.

Como já observava Canguilhem em 1980, o programa forte em NC saiu dos laboratórios. Vê-se o quanto o cérebro já se tornou uma personagem da imaginação contemporânea (Ehrenberg, 2008), com a valorização social do conhecimento do cérebro somada à literatura sobre a relação (de casal, paisfilhos, patrão-empregado etc.), no discurso público sobre as patologias mentais e sobre os bons comportamentos a adotar na vida cotidiana. Ou seja, uma linguagem naturalista está se difundindo na vida social, não se limitando ao cérebro.

Ehrenberg (2004 e 2008) chama a atenção para o fato de que esta valorização social do cérebro se apresenta como uma possibilidade de resposta aos problemas formulados pelo nosso ideal de autonomia individual generalizada. Em primeiro lugar, ela oferece a esperança de uma solução técnica para os sofrimentos banais derivados das exigências relativas às capacidades cognitivas e de controle emocional. Em segundo lugar, ela promove uma desestigmatização da incapacidade social, por exemplo, substituindo a ideia de deficiência pela noção de neurodiversidade, aumentando a autoestima dos que sofrem de síndrome de Asperger e de hiperatividade (os disabilities mouvements seriam uma nova linguagem da incapacidade social que reivindica 
a tolerância e o direito à diferença, apoiados numa referência ao cérebro). Finalmente, a valorização social do cérebro oferece um modo de justificar as dificuldades relacionais e as próprias ações dentro de um contexto, uma vez que os sujeitos não seriam mais responsáveis pelas suas dificuldades. Tais são as condições semânticas que o discurso da neurobiologia encontra em seu emprego no cotidiano.

Para concluir, Ehrenberg (2004) novamente recorre a François Jacob (1997) quando ele afirma haver, em biologia, mais generalizações do que teoria. O programa forte não estaria substituindo uma teoria por uma generalização? Bastaria apostar nas ferramentas da biologia molecular e desenvolver métodos que abandonem o trabalho conceitual sobre a natureza dos fenômenos estudados e sobre os quais queremos intervir? Quando os biólogos afirmam provar que tudo vem do interior (inclusive o social), eles não estariam substituindo a interioridade metafísica por uma interioridade biológica? Se forem descobertos os mecanismos cerebrais da culpa, da angústia, da vergonha, perderíamos por isso as razões para sentir culpa, angústia ou vergonha?

Ehrenberg encerra afirmando que, se somos equipados biologicamente para vivermos como seres sociais, o critério do mental não é a interioridade (cerebral ou subjetiva), mas a significação, ou seja, a normatividade social. Sem corpo, não há ser humano, mas sem vida social, sem mundo comum, também não. Por isso, Canguilhem (1980) terminou a conferência supracitada lembrando da conduta sem reservas do filósofo Spinoza diante do assassinato de seu amigo Jean de Wytt por orangistas, na cidade de Haia, em 1672, fixando nos muros um cartaz no qual se lia 'últimos bárbaros'. Com esta imagem, o mestre francês propõe que defendamos uma reserva com relação ao modo como querem que pensemos, ou seja, com relação ao pressuposto de que a subjetividade como um todo possa ser assimilada ao cérebro. Mas, defender nossa reserva significa, como fez Spinoza, sair dela ocasionalmente para nos opormos a qualquer intervenção estranha que implique privar o pensamento justamente de seu poder de reserva.

\section{Nota do editor}

Este texto foi produzido no âmbito do projeto de pesquisa "Do cérebro à palavra", apoiado pela Fundação Carlos Chagas Filho de Amparo à Pesquisa do Estado do Rio de Janeiro (Faperj) por intermédio da bolsa Jovem Cientista do Nosso Estado/2010. 


\section{Notas}

1 Professora do Departamento de Psicologia da Pontifícia Universidade Católica do Rio de Janeiro (PUC-Rio) e coordenadora da Pós-Graduação em Psicologia Clínica da PUC-Rio, Rio de Janeiro, Brasil. Doutora em Teoria Psicanalítica pela Universidade Federal do Rio de Janeiro (UFRJ). <winograd@uol.com.br>

Correspondência: Pontifícia Universidade Católica do Rio de Janeiro, Centro de Teologia e Ciências Humanas, Departamento de Psicologia, Rua Marquês de São Vicente, 225, sala 201, Edifício Cardeal Leme, Gávea, CEP 22543-900, Rio de Janeiro, RJ, Brasil.

\section{Referências}

APA. American Psychiatric Association. Benzodiazepine: Dependence, Toxicity and Abuse. A Task Force Report of the American Psychiatric Association. Washington, D.C.: APA, 1990.

Diagnostic and Statistical Manual of mental disorders. Washington, DC: APA, 1994.

CANGUILHEM, Georges. Le cerveau et la pensée. In: . Philosophe. Historien des Sciences. Actes du Colloque, 6-7-8 décembre 1990. Paris: Albin Michel, 1993. p. 11-33.

NAPPO, Solange A.; CARLINI, Eduardo. A. Benzodiazepínicos no Brasil: um perfil de consumo nos anos de 1988 e 1989. In:

(Org.). Medicamentos, drogas e saúde. São Paulo: Editora Hucitec; Sobravime, 1995. p. 119-129.

CASTEL, Pierre H. La querelle de l'hystérie: la formation du discours psychopathologique en France (1881-1913). Paris: PUF, 1998.

CEBRID. Centro Brasileiro de Informações sobre Drogas Psicotrópicas. 2003. Boletim do Cebrid, n. 47, jan./mar. 2003. Disponível em: <www.unifesp.br/dpsicobio/boletim/ ed48/11.htm>. Acesso em: 8 set. 2010.

COSTA, Jurandir F. Violência e psicanálise. Rio de Janeiro: Edições Graal, 1984.
EHRENBER, Alain. Le sujet cerebral. Esprit, Paris, n. 309, nov. 2004, p. 130-155.

. Le cerveau 'social', chimère épistémologique et vérité sociologique. Esprit, Paris, n. 341, jan. 2008, p. 79-103.

EHRENBERG, Alain; LOVELL, Anne M. La maladie mentale en mutation. Paris: Odile Jacob, 2001.

FREUD, Sigmund. Novas conferências introdutórias sobre psicanálise XXXI: a dissecção da personalidade psíquica. In: Sigmund Freud: obras completas. Rio de Janeiro: Zahar, 1969.

HORWITZ, Allan W.; WAKEFIELD. Jerome C. The Loss of Sadness how psychiatry transformed normal sorrow into depressive disorder. Oxford University Press, 2007.

ITABORAHY, Claudia. A Ritalina no Brasil: uma década de produção, divulgação e consumo. Dissertação (Mestrado em Medicina Social) - Instituto de Medicina Social, Universidade do Estado do Rio de Janeiro, 2009.

JACOB, François. La souris, la mouche et l'homme. Paris: Odile Jacob, 1997.

KESSLER, Ronald C. et al. Lifetime prevalence and age-of-onset distributions of mental 
disorders in the WHO's World Mental Health Survey Initiative. World Psychiatry, n. 6, 2007, p. 168-176.

The epidemiology of panic attacks, panic disorder, and agoraphobia in the National Comorbity Survey Replication. Arch Gen Psychiatry, v. 63, n. 4, 2006, p. 415-424.

LANE, Christopher. Shyness: How Normal Behavior Became a Sickness. New Haven; London: Yale University Press, 2007.

OMS. Organização Mundial de Saúde. La situation pharmaceutique dans le monde. Genebra: OMS, 1990.

ROSA, Bárbara P.; WINOGRAD, Monah. Sobre o mal-estar hoje: do cérebro à pulsão de morte. Não publicado.

SACKS, Oliver. The man who mistook his wife for a hat and other clinical tales. Londres: Picador, 1985.
WITtGenstein, Ludwig. Conversations on Freud. In: WOLLHEIM, R.; HOPKINS, J. Philosophical Essays on Freud. Cambridge, Cambridge University Press, 1982. p. 1-11.

WINOGRAD, Monah. Corps, cerveau et pensée. In: MASSON, C.; DESPRATS-PÉQUIGNOT, C. (Org.). Le corps contemporain: créations et faits de culture. Paris: L'Harmatann, 2009. p. 252-265.

WHO. World Health Organization. Mental Disorders in Primary Care. WHO Educational Package. Genebra: WHO, 1998.

Scaling up for mental, neurological, and substance use disorders. mhGAP. Genebra: WHO, 2008.

WONG, Ian C.K. et al. Psychotropic medications increased prescribing trends of paediatric. Archives of Disease in Childhood, n. 89, 2004, p. 1.131-1.132. 